\title{
foF2 Seasonal Prediction With IRI-2016 Over Quiet Activity at Dakar Station
}

\author{
Sibri Alphonse Sandwidi ${ }^{1}$, Christian Zoundi ${ }^{1}$, Doua Allain Gnabahou ${ }^{1} \&$ Frédéric Ouattara $^{1}$ \\ ${ }^{1}$ Research Laboratory for Energy and Space Weather, University Norbert ZONGO, BP 376 Koudougou, \\ Burkina Faso \\ Correspondence: Doua Allain Gnabahou, Head of Institut Universitaire de Technologie (IUT) of Université \\ Norbert ZONGO (UNZ), Koudougou, Burkina Faso. Tél: 226-7600-3164. E-mail: gnabahou@ yahoo.fr
}

Received: September 10, 2020

Accepted: October 26, 2020

Online Published: November 11, 2021

doi:10.5539/apr.v13n3p1

URL: https://doi.org/10.5539/apr.v13n3p1

\begin{abstract}
This study deals with comparison between Dakar station ionospheric F2 layer critical frequency (foF2) data and both subroutines (CCIR and URSI) of IRI-2016 model predictions. Dakar station is located near the crest of the African Equatorial Ionization Anomaly (EIA) region. Comparisons are made for very quiet activity during the four seasons (spring, summer, autumn and winter) over both solar cycles 21 and 22. The quietest days per season are determined by taking the five days with the lowest aa. The relative standard deviation of modeled foF 2 values is used to assess the quality of IRI model prediction. Model predictions are suitable with observed data by day than by night. The accuracy is better during spring season and poor during winter season. During all seasons, both model subroutines don't express the signature of the observed vertical drift $E \times B$. But they express an intense counter electrojet at the place of mean intensity or high electrojet.
\end{abstract}

Keywords: quiet geomagnetic activity, ionosphere, electrojet current, IRI-2016 model, seasonal prediction

\section{Introduction}

Experimental data comparison and model estimation is common in ionosphere study (Anderson, Mendillo, \& Herniter 1987; P. K. Bhuyan, Chamua, K. Bhuyan, Subrahmanyam \& Garg. 2003; Bilitza 1999; Gulyaeva 2012; Hajra et al. 2016; Oyeyemi, Poole, \& McKinnell 2005; Zhang, Xiao, Hao, Ridley \& Moldwin. 2011). The International Reference Ionosphere (IRI) is a joint undertaking by the Committee on Space Research (COSPAR) and the International Union of Radio Science (URSI), since the 1960s. This international standard's first version parameters of Earth's ionosphere dates from 1978 (Rawer, Bilitza, \& Ramakrishnan 1978). The IRI model has gradually improved every 5 years due to the new data acquired, but also to the advent of better modeling techniques and its latest version is IRI-2016 (Bilitza et al. 2017). IRI model permits several ionospheric parameters determination (e.g. ionosphere layer critical frequencies, ionosphere total electron content (TEC), bottom side thickness (B0) and bottom side shape (B1), electron density (Ne), etc.) (Bilitza et al. 2017; Bilitza et al. 2014; Sethi \& Mahajan 2002).

Several authors have worked on the comparison between observed ionospheric parameters and IRI model predictions (Adewale, Oyeyemi, \& Ofuase 2010; Bertoni et al. 2006; Chakraborty, Kumar, De \& Guha. 2014; Kumar, Tan, Razul, See \& Siingh. 2014; Nanema, Gnabahou, Zoundi \& Ouattara. 2018; Nanéma \& Ouattara 2013; Ouattara \& Nanéma 2014; Sandwidi, Gnabahou \& Ouattara 2020, Sethi, Dabas, \& Das 2007; Zhang, Paxton, Bilitza \& Doe. 2010). Like some of these papers, this study is focus in African Equatorial Ionization Anomaly (EIA) region. It concerns the comparison of the F2 layer critical frequency (foF2) variation as measured at Dakar station (Lat: $14.8^{\circ} \mathrm{N}$; Long: $342.6^{\circ} \mathrm{E}$ ) with both IRI-2016 subroutines prediction (CCIR and URSI) over quiet geomagnetic activities. The novelty of this paper is that on one hand it concerns the latest version of the IRI model (IRI-2016) and on another hand the comparison is made on seasonal variation.

The outline of the paper is as follows: section 2 concerns materials and methods; section 3 is devoted to results and discussions, and the conclusion ends the paper as its fourth section. 


\section{Materials and Methods}

\subsection{Data Used}

Three types of data are used in this article: (1) foF2 values measured at Dakar station. This station operated from 1950 to December 1996. Our study covers the period from 1976 to 1995, i.e. solar cycles 21 and 22 ; (2) Zurich sunspot number (Rz) for the influence of solar cycle phases and (3) Mayaud (1971; 1972; 1973; 1980) geomagnetic index aa for geomagnetic activity impacts. For this study, foF2 diurnal variation are analyzing by considering seasons impacts.

For comparison with IRI model values we use IRI-2016 version that can be ran through the website https://ccmc.gsfc.nasa.gov/modelweb/models/iri2016_vitmo.php.

\subsection{Methods}

\subsubsection{Geomagnetic Activity Determination}

Based on the strong correlation between geomagnetic index aa and solar wind velocity established by Svalgaard (1977), it is well-known, according to Legrand and Simon (1989), Ouattara and Amory-Mazaudier (2009), Ouattara and Zerbo (2011), Zerbo, Amory-Mazaudier, Ouattara, and Richardson. (2012), that disturbed activities are characterized by $a a>20 n T$ and are classified into three groups: (1) recurrent activities caused by solar high wind stream and Corotating interaction Region (CIRs). (2) shock activities caused by Coronal Mass Ejections (CMEs) and magnetic clouds and (3) fluctuating activities, consequences of solar heliosheet fluctuation.

To better study the impact of quiet geomagnetic activity on the season; very quiet days are not selected according to the reference limit previously defined by Zerbo, Ouattara, Zoundi, and Gyébré (2011) and Gnabahou and Ouattara (2012) but rather with the objective of selecting the quietest days of the considered month. Indeed, for a given month, Mayaud (1980) specifies that the quietest days are obtained by taking $a a<10 n T$. But here, our quietest days per month are determined by taking the five days with the lowest aa. Daily aa values are obtained from the following website: http://isgi.unistra.fr/data_download.php.

\subsubsection{Seasons Determination}

There are four seasons: (1) spring (March, April and May); (2) summer (June, July and August); (3) autumn (September, October and November) and (4) winter (December, January and February). But referring to the present paper, the Equinoctial month's concern March and September and that of solstice are June and December.

The retained days per solar cycle phases over selected months are mentioned in Table 1.

\subsubsection{Data Analysis Method}

This article aims to study foF2 hourly variations over seasons. To appreciate IRI model predictions, we will compare foF2 values from the URSI and CCIR subroutines of IRI-2016 model with those of Dakar station measured data. For this we will use error bars in the graphs given by the following equation:

$$
\sigma=\sqrt{V}
$$

where $\mathrm{V}$ is the variance defined by $\frac{1}{N} \sum_{i=1}^{N}\left(x_{i}-\bar{x}\right)^{2}$ with $x_{i}$ the foF2's hourly average value of considered days, $\bar{x}$ the average of the foF2's hourly average values and $\mathrm{N}$ the total number of observations.

Two types of analyzes will be carried out: (1) comparison between foF2 profiles and the five standard profiles established by Faynot and Vila (1979) for African equatorial ionization anomaly (EIA) region and (2) quantitative analysis based on comparison between foF 2 observed data profiles with those of both IRI-2016 subroutines. 
Table 1. The quietest days selected per season over solar cycle phases

\begin{tabular}{|c|c|c|c|c|c|c|c|c|c|c|c|c|c|c|c|c|c|c|c|c|c|}
\hline \multirow{4}{*}{$\begin{array}{c}\text { Seasons } \\
\text { Spring (March) }\end{array}$} & \multirow{3}{*}{$\begin{array}{c}\begin{array}{c}\text { Days / } \\
\text { Index }\end{array} \\
\text { Days }\end{array}$} & \multicolumn{20}{|c|}{ YEARS } \\
\hline & & \multicolumn{5}{|c|}{1976} & \multicolumn{5}{|c|}{1977} & \multicolumn{5}{|c|}{1979} & \multicolumn{5}{|c|}{1983} \\
\hline & & 21 & 22 & 23 & 24 & 25 & 3 & 4 & 5 & 19 & 31 & 12 & 13 & 14 & 20 & 21 & 7 & 8 & 9 & 10 & 27 \\
\hline & $\mathrm{Aa}$ & 10 & 4.6 & 11 & 6.1 & 7.6 & 7.6 & 5.6 & 7.1 & 9.1 & 7.8 & 7.5 & 6.1 & 2.7 & 9 & 9 & 14 & 12 & 13 & 14 & 5.5 \\
\hline \multirow{2}{*}{ Summer (June) } & Days & 9 & 14 & 15 & 21 & 22 & 6 & 7 & 11 & 12 & 15 & 1 & 3 & 5 & 12 & 28 & 3 & 4 & 7 & 25 & 30 \\
\hline & $\mathrm{Aa}$ & 6.5 & 5.8 & 6.3 & 4.7 & 5.8 & 9.3 & 9.3 & 5.8 & 7.2 & 6.3 & 9.1 & 8.2 & 9.2 & 9.2 & 6.5 & 12 & 6 & 9.8 & 8.6 & 13 \\
\hline \multirow{2}{*}{$\begin{array}{c}\text { Autumn } \\
\text { (September) }\end{array}$} & Days & 9 & 10 & 11 & 13 & 16 & 1 & 5 & 6 & 29 & 30 & 2 & 7 & 9 & 19 & 23 & 3 & 4 & 5 & 23 & 30 \\
\hline & $\mathrm{Aa}$ & 11 & 11 & 10 & 11 & 11 & 6.1 & 5.8 & 5.1 & 5.1 & 7.5 & 11 & 10 & 12 & 11 & 12 & 10 & 6.3 & 6.1 & 8.8 & 6 \\
\hline \multirow{2}{*}{$\begin{array}{c}\text { Winter } \\
\text { (December) }\end{array}$} & Days & 2 & 3 & 6 & 14 & 15 & 7 & 8 & 18 & 19 & 23 & 7 & 13 & 21 & 23 & 25 & 3 & 9 & 16 & 20 & 21 \\
\hline & $\mathrm{Aa}$ & 5.6 & 6.6 & 6.2 & 4.7 & 3.5 & 6.5 & 4 & 5.1 & 5.6 & 6.6 & 5.6 & 5.5 & 7 & 7.3 & 6.1 & 8.1 & 5.6 & 9.3 & 7.6 & 5.8 \\
\hline \multirow{2}{*}{ Seasons } & Days / & \multicolumn{20}{|c|}{ YEARS } \\
\hline & Index & \multicolumn{5}{|c|}{1986} & \multicolumn{5}{|c|}{1987} & \multicolumn{5}{|c|}{1990} & \multicolumn{5}{|c|}{1992} \\
\hline \multirow{2}{*}{ Spring (March) } & Days & 9 & 10 & 11 & 17 & 20 & 2 & 20 & 24 & 30 & 31 & 4 & 10 & 16 & 17 & 31 & 6 & 13 & 14 & 19 & 20 \\
\hline & $\mathrm{Aa}$ & 9.6 & 3.5 & 5.8 & 10 & 5.5 & 7.2 & 6.2 & 6.7 & 8.1 & 6.7 & 10 & 14 & 15 & 5.5 & 13 & 12 & 12 & 7.8 & 6.3 & 6.8 \\
\hline \multirow{2}{*}{ Summer (June) } & Days & 16 & 19 & 23 & 25 & 26 & 8 & 9 & 23 & 28 & 30 & 16 & 17 & 20 & 21 & 30 & 2 & 4 & 6 & 16 & 17 \\
\hline & $\mathrm{Aa}$ & 9.7 & 8.7 & 9.1 & 6.3 & 8.3 & 7.1 & 5.8 & 6.8 & 6.5 & 4.6 & 8.6 & 5.1 & 4.5 & 10 & 8.1 & 8.9 & 7.1 & 9 & 7.8 & 9.5 \\
\hline \multirow{2}{*}{$\begin{array}{c}\text { Autumn } \\
\text { (September) }\end{array}$} & Days & 7 & 8 & 16 & 22 & 30 & 3 & 4 & 5 & 18 & 19 & 2 & 3 & 27 & 29 & 30 & 1 & 12 & 13 & 24 & 27 \\
\hline & $\mathrm{Aa}$ & 9.8 & 8.5 & 10 & 6.2 & 8.6 & 6.5 & 16 & 13 & 13 & 7.2 & 6.4 & 7.5 & 16 & 14 & 9 & 3.9 & 9.5 & 10 & 7.8 & 7.5 \\
\hline \multirow{2}{*}{$\begin{array}{c}\text { Winter } \\
\text { (December) }\end{array}$} & Days & 5 & 8 & 15 & 28 & 29 & 8 & 13 & 27 & 28 & 30 & 10 & 11 & 19 & 21 & 29 & 5 & 6 & 16 & 25 & 26 \\
\hline & $\mathrm{Aa}$ & 6.2 & 8.1 & 6.6 & 5.2 & 5.1 & 2.7 & 6.6 & 2.7 & 5.2 & 5.8 & 4 & 5.1 & 5.8 & 7.3 & 7.4 & 13 & 15 & 14 & 11 & 8.9 \\
\hline
\end{tabular}

The five standard profiles established by Faynot and Vila are linked to the nature, the strength or the absence of electric currents in the E layer of ionosphere (Dunford, 1967; Acharya, Roy, Sivaraman, \& Dasgupta. 2010; Acharya, Roy, Sivaraman, \& Dasgupta, 2011; Vassal, 1982a; Vassal, 1982b). Those are: "Noon bite out" or "B" profile characterized by a double peak (morning and evening) with a trough around midday; "Reversed" or "R" profile characterized by a single peak at evening; "Morning pic" or "M" profile characterized by a single maximum at morning; "Plateau" or "P" profile characterized by an ionization plateau during daytime and "Dome profile" or " $D$ " profile characterized by a single maximum around noon. These five profiles express respectively signature of a high electrojet, an important afternoon conter-electrojet, moderate electrojet, a weak electrojet and absence of electrojet (Vassal 1982a; Vassal 1982b).

Assessment of foF2 measured data prediction's quality by both IRI-2016's subroutines will be done by analyzing the relative deviation of foF 2 defined by:

$$
\sigma_{f o F 2}=\frac{f o F 2_{m}-f o F 2_{\text {exp }}}{f o F 2_{\text {exp }}} \times 100
$$

where $f o F 2_{m}$ and $f o F 2_{\text {exp }}$ are respectively modeled and experimental foF2 values. $\sigma_{f o F 2}$ is the relative deviation with the following appreciation:

- $\sigma_{f o F 2}>10 \%$ model overestimates foF2's measured values;

- $\sigma_{f o F 2}<-10 \%$ model underestimates foF2's measured values;

$-\quad-10 \%<\sigma_{f o F 2}<10 \%$ model predictions are suitable.

\section{Results and Discussion}

\subsection{Results}

Figure 1 shows foF2 diurnal time variation in left column and relative deviation percentage ( $\sigma$ foF 2$)$ in right 
column for spring (panel "a"), summer (panel "b"), autumn (panel "c") and winter (panel "d") seasons of both solar cycles involved. Observed data from Dakar station are represented by solid line while IRI-2016 predictions are in dotted (for URSI) and in dash lines (for CCIR).

At spring (panel "a") model curves present " $\mathrm{R}$ " profiles while experimental data curve presents a " $\mathrm{B}$ " profile with a trough observed at local noon and an afternoon peak higher than the morning one. Experimental data afternoon peak is observed at $1700 \mathrm{LT}$, simultaneously with that of CCIR and one hour after that of URSI. Observed data profile shows the presence of a high electrojet (signature of the $E \times B$ drift) associated with an intense counter-electrojet. But only the latter, characterized by the afternoon peak, is observed for model predictions. Thus, IRI-2016's both subroutines don't show the upward vertical drift $E \times B$ in the spring. By day, URSI's curve is above that of CCIR and it's the opposite by night. ofoF2's curves show that the model overestimate experimental data during night for CCIR (1900-0500 LT) and for URSI (from 1900 to 0200 LT). Positive peaks are observed at 2300 LT for URSI $(+42.4 \%)$ and for CCIR $(+50.2 \%)$. URSI's negative peak $(-3.9 \%)$ is observed at $1000 \mathrm{LT}$ and that of CCIR, $(-5.6 \%)$ at $0700 \mathrm{LT}$. Thus, at spring URSI overestimates and underestimates the observed data more than CCIR. The previsions are better during the day than at night. Indeed, ofoF 2 curves present values within $\pm 10 \%$ for CCIR (from 0500 to 1900 LT) and for URSI (from 0200 to 2000 LT).

At summer (panel "b") all profiles are type "R". Experimental data curve's peak is observed at 1600 LT, simultaneously with that of URSI and one hour before that of CCIR. Model's profiles show the intense counter-electrojet observed in summer. $\sigma f o F 2$ curves show that both model subroutines overestimate observed data by night (2000-0500 LT) while they underestimate them in the morning, precisely for CCIR (0600 -0800 LT) and for URSI (from 0600 to 0700 LT). Positive peaks are observed at 0100 LT for URSI (+ 86\%) and for CCIR $(+105.4 \%)$. URSI's negative peak $(-13.3 \%)$ is observed at $0600 \mathrm{LT}$ and that of CCIR $(-26.4 \%)$ at 0700 LT. At summer, CCIR underestimates and overestimates observed data more than URSI. Nevertheless, one notes suitable predictions by the day than by night. Indeed, $\sigma$ foF 2 's curves present values within $\pm 10 \%$ from 0500 to 2000 LT for both subroutines, except from 0600 to 0700 LT for URSI and from 0600 to 0800 LT for CCIR.

At autumn (panel "c") model's curves show "R" profiles and the one of observed data shows a "B" profile with a late trough around $1400 \mathrm{LT}$ and an afternoon peak predominance. This afternoon peak is observed at $1700 \mathrm{LT}$, simultaneously with that of CCIR and one hour after that of URSI. Experimental data profile highlights an intense counter-electrojet associated with a strong electrojet around 1400 LT while model's profiles only show an intense counter-electrojet. Thus, IRI-2016 doesn't reproduce the upward vertical drift $E \times B$ during the fall. $\sigma f o F 2$ 's curves show that the model overestimate observed data during night, precisely from 1900 to 0500 LT for CCIR and from 2000 to 0500 LT for URSI and also during the day for URSI (1300-1500 LT). Negative peaks are observed at $0700 \mathrm{LT}$ for CCIR $(\mathbf{- 2 0 . 8} \%)$ and for URSI $(\mathbf{- 2 . 7} \%)$ and positive peaks at $2300 \mathrm{LT}$ for CCIR (+ 107. 8\%) and for URSI (84\%). In autumn, CCIR underestimates and overestimates experimental data more than URSI. Nevertheless, the predictions are suitable the day than by night with values of $\sigma f o F 2$ within $\pm 10 \%$ for URSI (from 0600 to 1300 LT and 1500 to 2000 LT) and for CCIR (from 0500 to 1900 LT, except between 0600 and $0800 \mathrm{LT}$ ).

At winter (panel "d") model curves present "R" profiles with an afternoon peak observed at $1700 \mathrm{LT}$ for CCIR and at $1600 \mathrm{LT}$ for URSI while experimental data curve shows an "M" profile associated with two troughs (the first at 1200 LT up to 1300 LT and the second at 1600 LT). Experimental data profile expresses a moderate electrojet's signature associated with two successive "strong electrojet", the first lasting from 1200 to 1300 LT and the second at $1600 \mathrm{LT}$. On other hand, model's predictions show the signature of an intense counter-electrojet. Thus, IRI-2016 doesn't reproduce the upward vertical drift $E \times B$ during winter. $\sigma f o F 2$ 's curves show that both model subroutines overestimate observed data by night (from 2100 to 2300) 


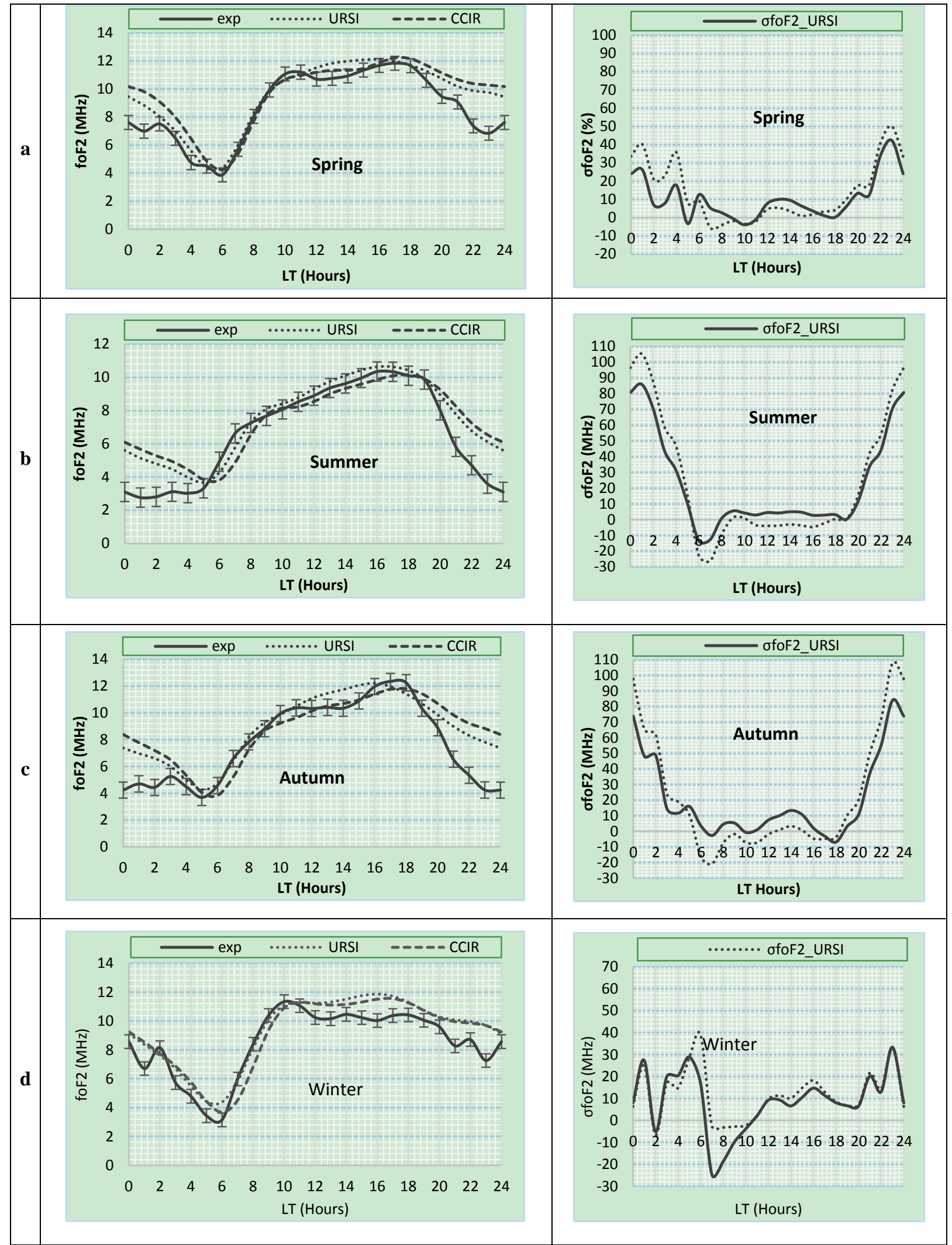

Figure 1. Seasonal diurnal variations profiles of foF2's measured data at Dakar station and those of IRI-2016 model (left column). Right column presents the relative deviations percentage curves of both model's subroutines (CCIR and URSI)

LT, around 0100 LT and from 0300 to 0600 LT) and also by day for URSI (1300-1700 LT) and for CCIR 
(1500-1700 LT). URSI's negative peak $(-3.2 \%)$ is observed at $0800 \mathrm{LT}$ and its positive peak $(+38.9 \%)$ at 0600 LT. CCIR's positive peak $(+33.3 \%)$ is observed at $2300 \mathrm{LT}$ and its negative peak $(-24.7 \%)$ at $0700 \mathrm{LT}$. CCIR underestimates observed data more than URSI while URSI overestimates them more than CCIR. Nevertheless, predictions are suitable the day than by night. $\sigma f_{o F}$ 's curves present values within $\pm 10 \%$ during night for both subroutines (around 0000 and $0200 \mathrm{LT}$ and from 1800 to $2000 \mathrm{LT}$ ) and also by day for URSI (0700-1200 LT) and for CCIR (0900-1400 LT).

\subsection{Discussion}

Generaly, experimental data's afternoon peak appears simultaneously with that of CCIR at 1700 LT and one hour after that of URSI during equinox seasons (spring and autumn). On other hand, during summer URSI's afternoon peak appears simultaneously at 1600 LT with that of experimental data and one hour before that of CCIR. But in winter, model curves show an afternoon peak while experimental data curve shows a morning peak. Also, model doesn't reproduce the upward vertical drift $E \times B$. This result is the same as that found by Ouattara (2013) and Ouattara and Nanema (2014) by comparing experimental data diurnal profiles from Ouagadougou station with those of IRI-2007 and IRI-2012 models predictions respectively.

Quantitative analysis of model predictions proves that predictions are better by day than by night (precisely from morning to 1900 LT for all seasons and around 2000 LT in summer). During all seasons, URSI's predictions are suitable for a longer time in the day than for CCIR, except in winter. This indicates as already demonstrated by Guibula, Zerbo, Kaboré, Ouattara (2019) at Korhogo station that URSI's predictions are better than CCIR's.

These results prove not only the importance to include the Equatorial Ionization Anomaly region ionosphere layer's electrodynamic mechanisms in the IRI model's configuration parameters. Indeed, the upward drift being equatorial zone characteristic phenomenon, it goes without saying that IRI model, parameterized with characteristic phenomena in particular in the mid-latitude zone, cannot reproduce the $E \times B$ drift as well as possible.

In addition, it is well known that at night, the predominant recombination processes in the F2 layer contribute to the drop in electron density; on other hand in high latitude regions this electron loss is compensated by electron precipitation phenomena in auroral zone. These high latitude regions electrodynamic phenomena could explain IRI-2016's poor prediction by night in equatorial region.

\section{Conclusion}

This paper shows that IRI-2016 model gives good prediction of foF2 variation at Dakar station, especially during day time. Model's peaks match those of observed foF2 data. In addition, model's subroutines don't express the signature of $E \times B$. They show intense counter-electrojet at the place of high or moderate electrojet. Predictions are better during spring and they are poor during winter. It would be important for next studies to quantify the variation of foF 2 in relation with electrodynamic phenomena characteristic of low latitudes such as the vertical drift velocity. This will allow us to be able to integrate those low latitudes region phenomena $(E \times B$ drift or electrojet, recombination processes, etc.) in the IRI model configuration parameters to improve its accuracy.

\section{Acknowledgment}

The authors thank Brest Telecom of Bretagne for providing Dakar ionosonde data. Many thanks to International Service of Geomagnetic Indices (ISGI) data center for providing data. We thank Dr. Dieter Bilitza and the IRI-2016 web master for permitting model access and model run.

\section{References}

Acharya, R., Roy, B., Sivaraman, M. R., \& Dasgupta, A. (2010). An Empirical Relation of Daytime Equatorial Total Electron Content with Equatorial Electrojet in the Indian Zone. Journal of Atmospheric and Solar-Terrestrial Physics, 72(9-10), 774-780. https://doi.org/10.1016/j.jastp.2010.03.023

Acharya, R., Roy, B., Sivaraman, M. R., \& Dasgupta, A. (2011). On Conformity of the EEJ Based Ionospheric Model to the Fountain Effect and Resulting Improvements. Journal of Atmospheric and Solar-Terrestrial Physics, 73(7-8), 779-784. https://doi.org/10.1016/j.jastp.2011.01.011

Adewale, A. O., Oyeyemi, E. O., \& Ofuase, U. D. (2010). Comparison between Observed Ionospheric foF2 and IRI-2001 Predictions over Periods of Severe Geomagnetic Activities at Grahamstown, South Africa. Advances in Space Research, 45(3), 368-373. https://doi.org/10.1016/j.asr.2009.09.026

Anderson, D. N., Mendillo, M., \& Herniter, B. (1987). A Semi-empirical Low-latitude Ionospheric Model. Radio Science, 22(2), 292-306. https://doi.org/10.1029/RS022i002p00292

Bertoni, F., Sahai, Y., Lima, W. L. C., Fagundes, P. R., Pillat, V. G., Becker-Guedes, F., \& Abalde, J. R. (2006). IRI-2001 Model Predictions Compared with Ionospheric Data Observed at Brazilian Low Latitude Stations. Ann. Geophys., 24, 2191-2200. https://doi.org/10.5194/angeo-24-2191-2006 
Bhuyan, P. K., Chamua, M., Bhuyan, K., Subrahmanyam, P., \& Garg, S. C. (2003). Diurnal, Seasonal and Latitudinal Variation of Electron Density in the Topside F-Region of the Indian Zone Ionosphere at Solar Minimum and Comparison with the IRI. Journal of Atmospheric and Solar-Terrestrial Physics 65(3), 359-368. https://doi.org/10.1016/S1364-6826(02)00294-8

Bilitza, D. (1999). Ionospheric Models for Radio Propagation Studies. Review of Radio Science, 2002, 625-679.

Bilitza, D., Altadill, D., Truhlik, V., Shubin, V., Galkin, I., Reinisch, B., \& Huang, X. (2017). International Reference Ionosphere 2016: From Ionospheric Climate to Real-time Weather Predictions. Space Weather, 15(2), 418-429. https://doi.org/10.1002/2016SW001593

Bilitza, D., Altadill, D., Zhang, Y., Mertens, C., Truhlik, V., Richard, P., ... Reinisch, B. (2014). The International Reference Ionosphere 2012-a Model of International Collaboration. Journal of Space Weather and Space Climate, 4(A07). https://doi.org/10.1051/swsc/2014004

Chakraborty, M., Kumar, S., De, B.K., \& Guha, A. (2014). Latitudinal Characteristics of GPS Derived Ionospheric TEC: A Comparative Study with IRI 2012 Model. Ann. Geophys, 57(5), A0539. https://doi.org/10.4401/ag-6438

Dunford, E. (1967). The Relationship between the Ionospheric Equatorial Anomaly and the E-Region Current System. Journal of Atmospheric and Terrestrial Physics, 29(12), 1489-1498. https://doi.org/10.1016/0021-9169(67)90102-X

Faynot, J. M., \& Vila, P. (1979). F region strata at the Magnetic Equator. Annals of Geophysics, 35, 1-9. Retrieved from https://ui.adsabs.harvard.edu/abs/1979AnG....35....1F

Gnabahou, D. A., \& Ouattara, F. (2012). Ionosphere Variability from 1957 to 1981 at Djibouti Station. European Journal of Scientific Research, 73(3), 382-390. Retrieved from http://www.europeanjournalofscientificresearch.com

Guibula, K., Zerbo, J.-L., Kaboré, M., \& Ouattara, F. (2019). Critical Frequency foF2 Variations at Korhogo Station from 1992 to 2001 Prediction with IRI-2012. International Journal of Geophysics, 2019. https://doi.org/10.1155/2019/2792101

Gulyaeva, T. L. (2012). Empirical Model of Ionospheric Storm Effects on the F2 Layer Peak Height Associated with Changes of Peak Electron Density. Journal of Geophysical Research: Space Physics, 117(A2). https://doi.org/10.1029/2011JA017158

Hajra, R., Chakraborty, S. K., Tsurutani, B. T., Dasgupta, A., Echer, E., Brum, C. G. M., ... Sobral, J. H. A. (2016). An Empirical Model of Ionospheric Total Electron Content (TEC) near the Crest of the Equatorial Ionization Anomaly (EIA). Journal of Space Weather and Space Climate, 6(A29). https://doi.org/10.1051/swsc/2016023

Kumar, S., Tan, E. L., Razul, S. G., See, C. M. S., \& Siingh, D. (2014). Validation of the IRI-2012 Model with GPS-Based Ground Observation over a Low-Latitude Singapore Station. Earth, Planets and Space, 66(1), 17. https://doi.org/10.1186/1880-5981-66-17

Legrand, J.-P., \& Simon, P. A. (1989). Solar Cycle and Geomagnetic Activity: A Review for Geophysicists. Part I. The Contributions to Geomagnetic Activity of Shock Waves and of the Solar Wind. Annales Geophysicae, 7(6), 565-593.

Liu, L., Wan, W., Ning, B., Zhang, M.-L., He, M., \& Yue, X. (2010). Longitudinal Behaviors of the IRI-B Parameters of the Equatorial Electron Density Profiles Retrieved from FORMOSAT-3/COSMIC Radio Occultation Measurements. Advances in Space Research, 46(8), 1064-1069. https://doi.org/10.1016/j.asr.2010.06.005

Mayaud, P. N. (1971). Une Mesure Planétaire D’activité Magnétique Basée Sur Deux Observatoires Antipodaux. Ann. Geophys, 27(1), 67-70.

Mayaud, P. N. (1972). The Aa Indices: A 100-year Series Characterizing the Magnetic Activity. Journal of Geophysical Research, 77(34), 6870-6874. https://doi.org/10.1029/JA077i034p06870

Mayaud, P. N. (1973). A Hundred Year Series of Geomagnetic Data, 1868-1967: Indices Aa, Storm Sudden Commencements. IAGA Bulletin, 33, 256.

Mayaud, P. N. (1980). Derivation, Meaning, and Use of Geomagnetic Indices. American Geophysical Union: Advanced Earth and Space Science, 22. Retrieved from https://agupubs.onlinelibrary.wiley.com/doi/book/10.1029/GM022

Nanema, E., Gnabahou, D. A., Zoundi, C., \& Ouattara, F. (2018). Modeling the Ionosphere during Quiet Time Variation at Ouagadougou in West Africa. International Journal of Astronomy and Astrophysics, 8(2), 
163-170. https://doi.org/10.4236/ijaa.2018.82011

Nanéma, E., \& Ouattara, F. (2013). HmF2 Quiet Time Variations at Ouagadougou and Comparison with IRI-2012 and TIEGCM Predictions during Solar Minimum and Maximum. Archives of Applied Science Research, 5(5), 55-61. Retrieved from http://scholarsresearchlibrary.com/archive.html

Ouattara, F. (2013). IRI-2007 foF2 Predictions at Ouagadougou Station during Quiet Time Periods from 1985 to 1995. Archives of Physics Research, 4(3), 12-18.

Ouattara, F., \& Amory-Mazaudier, C. (2009). Solar-geomagnetic Activity and Aa Indices toward a Standard Classification. Journal of Atmospheric and Solar-Terrestrial Physics, 71(17-18), 1736-1748. https://doi.org/10.1016/j.jastp.2008.05.001

Ouattara, F., \& Nanéma, E. (2014). Quiet Time foF2 Variation at Ouagadougou Station and Comparison with TIEGCM and IRI-2012 Predictions for 1985 and 1990. Physical Science International Journal, 4, 892-902. https://doi.org/10.9734/PSIJ/2014/9748

Ouattara, F., \& Zerbo, J.-L. (2011). Ouagadougou Station F2 Layer Parameters, Yearly and Seasonal Variations during Severe Geomagnetic Storms Generated by Coronal Mass Ejections (CMEs) and Fluctuating Wind Streams. International Journal of Physical Sciences, 6(20), 4854-4860. https://doi.org/10.5897/IJPS10.470

Oyeyemi, E. O., Poole, A. W. V., \& McKinnell, L. A. (2005). On the Global Model for foF2 Using Neural Networks. Radio Science, 40(6), 1-15. https://doi.org/10.1029/2004RS003223

Rawer, K., Bilitza, D., \& Ramakrishnan, S. (1978). Goals and Status of the International Reference Ionosphere. Reviews of Geophysics, 16(2), 177-181. https://doi.org/10.1029/RG016i002p00177

Sandwidi, S. A., Gnabahou, D. A., \& Ouattara, F. (2020). foF2 prediction with IRI-2016 at Dakar Station duringquiet activity over solar cycles 21 and 22. International Journal of Physical Sciences, 15(4), 194-200. https://doi.org/10.5897/IJPS2020.4906

Sethi, N. K., Dabas, R. S., \& Das, R. M. (2007). Diurnal and Seasonal Variation of B0, B1 Parameters during High Solar Activity Period at Low Mid-Latitude and Their Comparisons with IRI-2001 Model. Journal of Atmospheric and Solar-Terrestrial Physics, 69(7), 767-774. https://doi.org/10.1016/j.jastp.2007.01.008

Sethi, N. K., \& Mahajan, K. K. (2002). The Bottomside Parameters B0, B1 Obtained from Incoherent Scatter Measurements during a Solar Maximum and Their Comparisons with the IRI-2001 Model. Ann. Geophys., 20, 817-822. https://doi.org/10.5194/angeo-20-817-2002, 2002.

Svalgaard, L. (1977). Geomagnetic Activity: Dependence on Solar Wind Parameters. STANFORD UNIV CALIF INST FOR PLASMA RESEARCH.

Vassal, J. (1982). Electrojet, Contre-Électrojet et Région F À Sarh (Tchad). Géophysique, (19), 3-9.

Vassal, J. (1982b). La Variation Du Champ Magnétique et Ses Relations Avec I'électrojet Équatorial Au Sénégal Oriental. Ann. Geophys, 38, 347-355.

Zerbo, J.-L., Amory Mazaudier, C., Ouattara, F., \& Richardson, J. D. (2012). Solar wind and geomagnetism: toward a standard classification of geomagnetic activity from 1868 to 2009. Ann. Geophys., 30, 421-426. https://doi.org/10.5194/angeo-30-421-2012

Zerbo, J.-L., Ouattara, F., Zoundi, C., \& Gyébré A. M. F. (2011). Solar Cycle 23 and Geomagnetic Activity since 1868. La Revue CAMES: La Série A, 12(2), 255-262.

Zhang, D-H., Xiao, Z., Hao, Y.-Q., Ridley, A. J., \& Moldwin, M. (2011). Modeling Ionospheric foF2 by Using Empirical Orthogonal Function Analysis. Annales. Geophysicae, 29, 1501-1515. https://doi.org/10.5194/angeo-29-1501-2011

Zhang, Y., Paxton, L. J., Bilitza, D., \& Doe, R. (2010). Near Real-Time Assimilation in IRI of Auroral Peak E-Region Density and Equatorward Boundary. Advances in Space Research, 46(8), 1055-1063. https://doi.org/10.1016/j.asr.2010.06.029

\section{Copyrights}

Copyright for this article is retained by the author(s), with first publication rights granted to the journal.

This is an open-access article distributed under the terms and conditions of the Creative Commons Attribution license (http://creativecommons.org/licenses/by/4.0/). 